\title{
Feeding behavior of Aplysia: A model system for comparing cellular mechanisms of classical and operant conditioning
}

\author{
Douglas A. Baxter ${ }^{1}$ and John H. Byrne \\ Department of Neurobiology and Anatomy, W.M. Keck Center for the Neurobiology of Learning and Memory, The University of \\ Texas Medical School at Houston, Houston, Texas 77030, USA
}

\begin{abstract}
Feeding behavior of Aplysia provides an excellent model system for analyzing and comparing mechanisms underlying appetitive classical conditioning and reward operant conditioning. Behavioral protocols have been developed for both forms of associative learning, both of which increase the occurrence of biting following training. Because the neural circuitry that mediates the behavior is well characterized and amenable to detailed cellular analyses, substantial progress has been made toward a comparative analysis of the cellular mechanisms underlying these two forms of associative learning. Both forms of associative learning use the same reinforcement pathway (the esophageal nerve, En) and the same reinforcement transmitter (dopamine, DA). In addition, at least one cellular locus of plasticity (cell B51) is modified by both forms of associative learning. However, the two forms of associative learning have opposite effects on B51. Classical conditioning decreases the excitability of B51, whereas operant conditioning increases the excitability of B51. Thus, the approach of using two forms of associative learning to modify a single behavior, which is mediated by an analytically tractable neural circuit, is revealing similarities and differences in the mechanisms that underlie classical and operant conditioning.
\end{abstract}

In their habitat, animals face a constantly changing environment. It is advantageous if the more salient aspects of the environment can be predicted. Operant and classical conditioning constitute important processes by which predictive memory is acquired. In classical conditioning, an initially neutral event (conditioned stimulus, CS) that precedes an important event (unconditioned stimulus, US) may come to function as a predictor of the US. Following the association between CS and US, the animal will produce anticipatory behavior (conditioned response, CR) when presented with the CS (Pavlov 1927). In operant conditioning, an animal learns to anticipate an important event (reward or punishment) that consistently occurs as a result of the animal's own behavior (the operant). By forming an association between the operant and reinforcement, the animal learns the consequences of its behavior and changes the frequency of the operant accordingly (Thorndike 1911; Skinner 1938). Thus, these forms of learning constitute important adaptive mechanisms for behavior.

A fundamental problem in neuroscience is to understand events occurring within individual neurons and within networks that contribute to learning and memory. For example, what cellular processes detect the coincidence between stimuli during classical conditioning, or between behavior and consequences during operant conditioning? What are the neural substrates that store this information? How are subsequent behaviors modified? Although these forms of associative learning can be distinguished procedurally, are the mechanisms underlying operant and classical conditioning similar or different? And if so, at what organizational level?

The consummatory phase of feeding behavior in Aplysia exhibits several features that make it an attractive model system with which to study associative learning. The behavior can be

\footnotetext{
'Corresponding author.
}

E-mail Douglas.Baxter@uth.tmc.edu; fax (713) 500-0623.

Article is online at http://www.learnmem.org/cgi/doi/10.1101//m.339206. modified by both classical and operant conditioning (Susswein and Schwartz 1983; Susswein et al. 1986; Colwill et al. 1997; Botzer et al. 1998; Lechner et al. 2000a; Brembs et al. 2002; Katzoff et al. 2002; Lorenzetti et al. 2006b). The behavior occurs in an all-or-nothing fashion and is therefore easily quantified (Brembs et al. 2002). In addition, the neural circuitry underlying the behavior is well characterized and amenable to detailed cellular and molecular analysis (for recent reviews, see Elliott and Susswein 2002; Cropper et al. 2004). This review summarizes recent advances in a comparative analysis of the cellular mechanisms that underlie appetitive classical conditioning and reward operant conditioning of feeding behavior, specifically biting. Both forms of associative learning share a common reinforcement pathway (the esophageal nerve, En) and both use dopamine (DA) as a reinforcement transmitter. Moreover, both forms of associative learning share at least one cellular locus of plasticity, cell B51, which is believed to make a critical contribution to feeding behavior. However, the two forms of associative learning have opposite effects on B51. Classical conditioning decreases the excitability of B51, whereas operant conditioning increases the excitability of B51. Thus, these two forms of associative learning appear to differ at the cellular level.

\section{Feeding behavior, motor patterns, and the feeding} neural network

\section{Feeding behavior and its neural network}

Consummatory feeding in Aplysia consists of a series of rhythmic movements involving the peri-oral structures and the foregut, including the mouth (lips and jaws), buccal mass (odontophore and radula), and esophagus (for review, see Kupfermann 1974; Kandel 1979; Elliott and Susswein 2002; Cropper et al. 2004). Ingestion draws food into the mouth, through the buccal cavity and toward the esophagus. During ingestion, the odontophore, with its two radula halves (toothed grasping surfaces), is first rotated forward toward the mouth (i.e., protraction) and the jaws 
open to accommodate the protracting odontophore. Initially, the two halves of the radula are separated during protraction, but before the peak of protraction, they begin to close and grasp the food. The radula remains closed as the odontophore retracts (backward rotation), which brings the food into the mouth and buccal cavity, and the jaws close as the odontophore retracts (Morton and Chiel 1993a) (for an example of ingestion, see the video clip included in the Supplemental material in Brembs et al. 2002). In addition to ingestion, the foregut produces rejection movements in response to inedible or distasteful objects taken into the buccal cavity (Morton and Chiel 1993a). During rejection, the two halves of the radula are closed as the odontophore protracts toward the mouth and they are open as the odontophore retracts, which ejects the inedible object from the buccal cavity. Thus, consummatory feeding behaviors can be described as having two phases: a protraction phase followed by a retraction phase. During ingestion the radula is closed during the retraction phase, whereas, during rejection, the radula is open during the retraction phase.

The neural circuitry that mediates consummatory feeding behavior is located primarily in the cerebral and buccal ganglia (for recent reviews, see Elliott and Susswein 2002; Cropper et al. 2004). As a result of work in several laboratories, this circuitry is beginning to be understood. Figure 1 illustrates several elements of the neural circuitry for feeding behavior that have been well characterized. For purposes of this discussion, this circuit can be loosely organized into a hierarchy. The cerebral ganglia contain sensory afferents that mediate tactile information (e.g., cerebral mechanoafferents [CM]; Rosen et al. 1979, 1982) and the cerebral ganglia receive chemosensory information (Xin et al. 1995) from the lips and other regions of the head. Mechanosensory and chemosensory inputs converge onto cerebral-buccal interneurons (e.g., CBI-2), some of which can elicit neural activity for feeding behavior. These higher-order neurons are therefore referred to as command-like neurons (Rosen et al. 1991; Morgan et al. 2000; Sanchez et al. 2000; Jing and Weiss 2001; Sanchez and Kirk 2001; Morgan et al. 2002; Sanchez and Kirk 2002; Jing and Weiss 2005; for review, see Kupfermann and Weiss 2001). The motor activity that controls the rhythmic movements of the odontophore and radula is generated by a central pattern generator (CPG) in the buccal ganglia (e.g., Susswein and Byrne 1988; Church and Lloyd 1994; Horn and Kupfermann 2002).

\section{Motor patterns and neural activity underlying feeding movements}

Many previous studies have utilized a variety of intact, semiintact, and reduced preparations to relate specific patterns of neural activity to aspects of consummatory feeding behaviors. For example, Morton and Chiel (1993a) combined video recordings of consummatory feeding behaviors with extracellular recordings of buccal nerve activity in intact animals. Two patterns of neural activity (buccal motor patterns [BMPs]) were characterized, one recorded during ingestion and the other recorded during rejection. The two BMPs were distinguished by the timing of large-unit activity in the radula nerve (Rn) relative to the onset of activity in the buccal nerve 2 (n2). During ingestion, large-unit activity in the two nerves primarily overlapped (see insert in Fig. 1), whereas, during rejection, large-unit activity in Rn preceded that in n2. Moreover, extracellular recordings from behaving animals were later associated with intracellular recordings from identified neurons in a reduced preparation (Morton and Chiel 1993b; see also Church and Lloyd 1994; Orekhova et al. 2001; Horn et al. 2004; Jing et al. 2004; Ye et al. 2006). The large-unit activity that was recorded extracellularly in Rn corresponded to activity in closer motor neurons $\mathrm{B} 8 \mathrm{a} / \mathrm{b}$ and one of the large units that was recorded extracellularly in $\mathrm{n} 2$ corresponded to activity in retractor motor neuron B10. Thus, during ingestion BMPs,

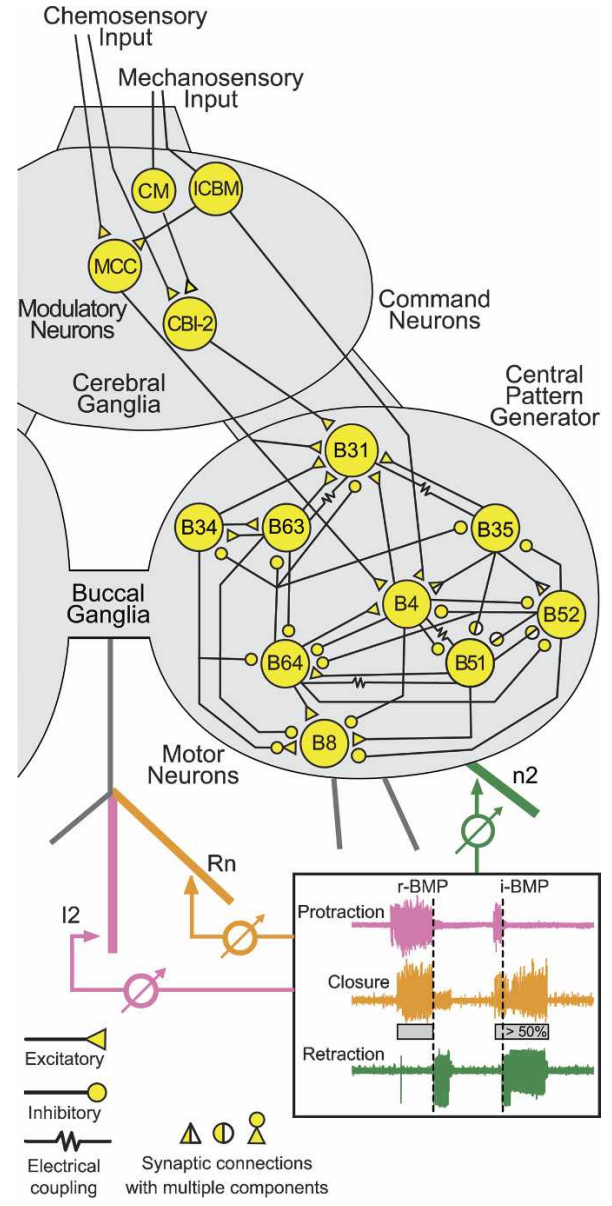

Figure 1. Several elements of the neural circuit for feeding behavior Sensory neurons in the cerebral ganglion (i.e., cerebral mechanoafferents, CM) mediate tactile stimuli from the lips. A subclass of CM cells (i.e., interganglionic cerebral buccal mechanoafferents, ICBM) projects to the buccal ganglion. Chemosensory cells are thought to have cell bodies in the periphery and project to neurons in the cerebral ganglia. Cerebralto-buccal interneurons $(\mathrm{CBI})$ receive mechanosensory and chemosensory input and project to the central patter generator (CPG) in the buccal ganglia. Some CBIs (e.g., CBI-2) can evoke patterned activity in the CPG and are therefore referred to as command-like neurons. Some of the neurons in the CPG can be assigned functional roles. For example, B31/ 32 and B63 play important roles in initiating buccal motor patterns (BMPs) and maintaining the protraction phase of a BMP. B64 plays an important role maintaining the retraction phase. B4/5, B34, and B51 play important roles in switching the activity of the CPG between and rejection- and ingestion-like BMPs. The expression of activity for ingestion or rejection is determined by the phase relationship of activity in closure motor neurons (e.g., B8) and the protraction/retraction cycle. Patternswitching neurons shift the closure activity either toward the protraction phase to produce rejection-like BMPs (e.g., B4/5) or toward the retraction phase to produce ingestion-like BMPs (e.g., B51). Patterned activity is terminated, in part, by activity in neuron B52. The circuitry for feeding behavior is under the control of a number of modulatory neurons, such as the serotonergic metacerebral cell (MCC). Note that this diagram is not a comprehensive description of available data on identified neurons and synaptic connections involved in the control, expression, and modulation of feeding behavior. The inset illustrates two BMPs with the protraction, closure, and retraction activity monitored from peripheral nerves $12, R n$, and n2, respectively. One of the BMPs is an example of an ingestion-like BMP (i-BMP) and the other is an example of a rejection-like BMP (r-BMP). A BMP was classified as ingestion-like if $50 \%$ or more of the large-unit activity in $\mathrm{Rn}$, which represents activity in radula closure motor neurons, occurred after the end of the burst in the 12 nerve, which represents activity in radula protraction motor neurons. A BMP was classified as rejection-like if the large-unit activity in $\mathrm{Rn}$ did not extend beyond the burst in the 12 nerve. The gray boxes that are below the middle trace indicate the duration of large-unit activity in the Rn. (Modified with permission from The Society for Neuroscience (c) 2000, Lechner et al. 2000b.) 
activity in closer and retractor motor neurons coincided (i.e., overlapping large-unit activity in $\mathrm{Rn}$ and $\mathrm{n} 2$ ), whereas, during rejection-like BMPs (r-BMPs), activity in closer motor neurons preceded the activity in retractor motor neurons. These studies provide a useful framework or set of criteria for evaluating the potential behavioral relevance of patterns of neural activity observed in more reduced preparations.

Reduced preparations of isolated ganglia retain the ability to express patterns of neural activity similar to those previously recorded in vivo (e.g., Susswein and Byrne 1988; Morton and Chiel 1993b; Nargeot et al. 1997, 1999a,b; Kabotyanski et al. 2000; Jing and Weiss 2001; Hurwitz et al. 2003). This feature has facilitated analysis of the role of specific cellular components of the buccal CPG (Fig. 1) in the generation of BMPs. For example, B51, a neuron pivotal for the production of ingestion-like BMPs (Nargeot et al. 1999a,b), exhibits a characteristic, sustained, allor-nothing level of activity (plateau potential) (Plummer and Kirk 1990) during ingestion-like BMPs, but not during rejection BMPs (Nargeot et al. 1999a). Moreover, direct depolarization of B51 during a BMP enhances the production of ingestion-like BMPs, whereas hyperpolarization inhibits ingestion-like BMPs (Nargeot et al. 1999a).

\section{Associative learning and feeding behavior}

\section{Appetitive classical conditioning}

Lechner et al. (2000a) developed a training protocol for classical conditioning of biting in Aplysia that produced both short- and long-term memory. The procedure was similar to one developed earlier by Colwill et al. (1997). Conditioning was accomplished by delivering paired presentations of a conditioned stimulus (CS, tactile stimulation of the lips with a soft paintbrush) with an unconditioned stimulus (US, seaweed) (Fig. 2). The effects of conditioning were assessed by counting the number of bites elicited by CS test stimuli, which were delivered prior to training (pretest) and 1 or $24 \mathrm{~h}$ after training (post-test). At both time points after training, paired training produced a significant increase in the number of bites (post-test minus pre-test) as compared to unpaired training (Fig. 3). These data indicate that feeding behavior in Aplysia can be classically conditioned and that the associative memory persists for at least $24 \mathrm{~h}$. This finding provided the basis for subsequent cellular analyses (see below).

\section{Identifying the reinforcement pathway}

In the classical conditioning procedure, the animal is allowed to ingest the seaweed (i.e., the US). Thus, the US activates sensory pathways both from the lips and from the foregut. To analyze which of these pathways mediate the conditioning, the US presentation was manipulated to stimulate only the lip region (Lechner et al. 2000a). This stimulus (i.e., touching the lips with seaweed) reliably elicited bites (i.e., the UR). During training, animals received either paired or unpaired CS/US presentations in which seaweed (i.e., the US) was brought into contact with the lips, but the animal was not allowed to ingest the food. A separate group of animals received training in which they were allowed to ingest the food. Learning was evaluated $1 \mathrm{~h}$ after training. Only animals that received paired training and that were allowed to ingest the food displayed a significant increase in the number of bites. These data provide evidence that the sensory pathways originating from the lips of the animals do not support conditioning and suggest the US pathway originates in the foregut.

Schwarz and Susswein $(1984,1986)$ found that an intact esophageal nerve (En) was necessary for Aplysia to learn a food was inedible, which suggests En conveys information about the presence of food in the gut during ingestive behavior and may mediate reinforcement during associative learning. To provide additional insights into the potential role of En as a reinforcement pathway, extracellular recordings of nerve activity were made in freely behaving Aplysia via chronically implanted extracellular hook-electrodes on the En (Brembs et al. 2002). Little nerve activity was observed during biting in the absence of food. In contrast, brief $(\sim 3 \mathrm{sec})$ bursts of high-frequency $(\sim 30 \mathrm{~Hz})$ nerve activity were recorded in En during the ingestion of food. This observation suggests that the En conveys afferent information related to the US.

To examine the role of afferent pathways originating from the foregut in classical conditioning, the anterior branch of esophageal nerve $\left(\mathrm{En}_{2}\right)$ was surgically lesioned (Lechner et al. 2000a). Animals with bilateral lesions of the $\mathrm{En}_{2}$ received paired or unpaired CS/US presentations and were compared with similarly trained sham operated animals. $\mathrm{En}_{2}$ lesions did not hamper the ability of animals to bite and ingest small pieces of food (e.g., the US during conditioning). However, $1 \mathrm{~h}$ after training, only the sham operated animals demonstrated a pairing-specific increase in bites elicited by the test CS. These data suggest that the afferent pathways originating in the foregut play a key role in mediating the US in appetitive classical conditioning of feeding in Aplysia. Whether the fibers within $\mathrm{En}_{2}$ themselves or some downstream targets of these fibers mediate the modulation is not known.

\section{Neural correlates of in vivo classical conditioning}

Lechner et al. (2000b) developed an in vitro preparation to study the cellular correlates of classical conditioning. The preparation consisted of the cerebral and buccal ganglia taken from animals soon after they had been classically conditioned. Brief electrical

A

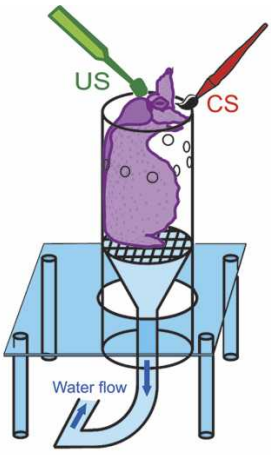

B
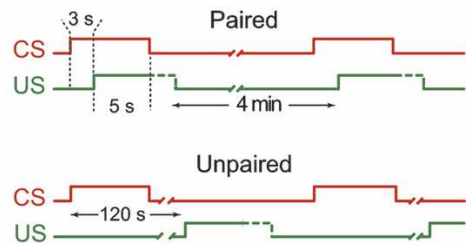

$\mathrm{C}_{\mathrm{P}}$

\begin{tabular}{|c|c|c|c|c|c|c|c|c|c|c|c|}
\hline Pre-test & & & & & ainir & & & & & & Post-test \\
\hline $\begin{array}{c}\text { CSs } \\
111\end{array}$ & $\stackrel{\mathrm{T} 1}{\mathrm{~L}}$ & $\stackrel{\mathrm{T} 2}{1}$ & T3 & $\stackrel{\mathrm{T} 4}{\perp}$ & T5 & $\stackrel{\text { T6 }}{1}$ & $\stackrel{\mathrm{T}}{\mathrm{1}}$ & $\stackrel{\mathrm{T}}{1}$ & $\stackrel{\text { T9 }}{1}$ & T10 & CSs \\
\hline
\end{tabular}

Figure 2. Classical conditioning of feeding behavior in vivo. ( $A$ ) Animals were restrained in clear plastic tubes, which facilitated stimulation of the mouth and lips. Tactile stimulation of the lips with a paintbrush served as the conditioned stimulus (CS) and food as the unconditioned stimulus (US). (B) Schematic representation of the classical conditioning stimulus protocol. A delayed pairing procedure was used in which the CS onset preceded the US onset by $3 \mathrm{sec}$. CS and US overlapped for $5 \mathrm{sec}$, after which the CS was terminated. The US was presented until the animal ingested it, but no longer than $60 \mathrm{sec}$. Unpaired training consisted of CS and US presentations at an inter-stimulus-interval (ISI) of $120 \mathrm{sec}$. The inter-trial-interval (ITI) was $4 \mathrm{~min}$ in all experiments. Note, the broken lines indicate that the timeline is not drawn to scale. (C) Immediately before training animals received four CS presentations (pre-test). The number of bites during this stimulation period was counted. Subsequently, animals received 10 trials of paired or unpaired training. After training the number of bites elicited by four CSs (post-test) was determined, and the change in the number of bites was calculated by subtracting the pre-test score from the post-test score. The post-test CSs were presented either 1 or $24 \mathrm{~h}$ after training (see Fig. 3). (Modified with permission from The Society for Neuroscience (c) 2000, Lechner et al. 2000a.) 
A. $1 \mathrm{hr}$ after training

B. $24 \mathrm{hr}$ after training
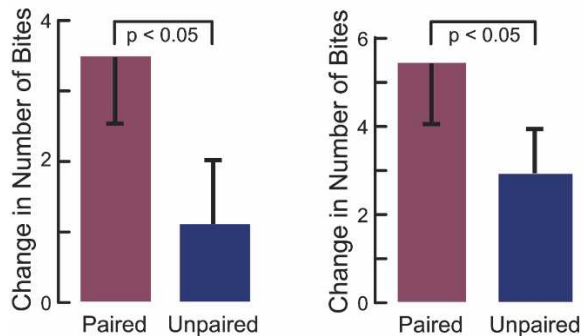

Figure 3. Short- and long-term memory following classical conditioning of feeding behavior. (A) One-hour retention for classical conditioning of feeding behavior. Conditioning was measured as a change in the number of CS-elicited bites (i.e., post-test minus pre-test). Paired training produced a significantly greater change in the number of CS-elicited bites as compared to unpaired training. (B) In a separate group of animals, the retention for classical conditioning of feeding behavior was measured 24 $\mathrm{h}$ after training. At $24 \mathrm{~h}$ following training, paired training produced a significantly greater change in the number of CS-elicited bites as compared to unpaired training. (Modified with permission from The Society for Neuroscience $\odot$ 2000, Lechner et al. 2000a.)

stimulation of nerve $\mathrm{AT}_{4}$, the most medial and ventral branch of the anterior tentacle nerve (AT) which innervates the lips and contains axons of mechanoafferents, was used as the in vitro representation of the CS. BMPs represented fictive feeding responses. In preparations taken from animals that previously received paired training, stimulation of the $\mathrm{AT}_{4}$ nerve evoked a significantly greater number of BMPs as compared to preparations from animals that previously had received unpaired training. This effect was specific for $\mathrm{AT}_{4}$-evoked BMPs, as the number of spontaneously occurring BMPs was not different between the paired and unpaired groups. These results suggest that correlates of classical conditioning can be observed and studied in preparations of isolated ganglia. Furthermore, these data indicate that neural correlates of classical conditioning are specific to CSevoked activity without affecting the spontaneous activity of the CPG.

Additional analysis of CS-evoked BMPs revealed that the increase in BMPs following paired training was almost exclusively attributable to an increase in the number of ingestion-like BMPs. These data indicate that classical conditioning of feeding induces specific changes in the neural circuitry that controls feeding behavior resulting in increased ingestion-like motor activity. Importantly, this effect closely mimics the effect of behavioral conditioning (i.e., an increase in the number of bites in response to tactile stimulation of the lip), thereby helping to validate the use of the in vitro preparation to study neural correlates of classical conditioning.

Given that classical conditioning changes activity in the neural circuitry mediating feeding behavior, several sites were investigated within the buccal CPG where plasticity might occur. Because B31/32 plays a key role in initiating BMPs (Susswein and Byrne 1988; Hurwitz et al. 1994, 1996, 2003; Dembrow et al. 2004), we investigated whether conditioning altered the intrinsic properties of B31/32 (Fig. 4A; Lechner et al. 2000b). Neither the input resistance nor resting membrane potential of B31/32 were affected by conditioning. In contrast, paired training significantly increased the excitation of B31/32 that is elicited by stimulating the CS pathway. The input from the CS pathway to B31/32 was assessed by analyzing the complex postsynaptic potential (CPSP) that is induced in B31/32 during stimulation of $\mathrm{AT}_{4}$ (Fig. 4A1). The peak depolarization (Fig. 4A2) and integrated area (Fig. $4 \mathrm{~A} 3$ ) of the $\mathrm{AT}_{4}$-evoked cPSP in $\mathrm{B} 31 / 32$ were greater in ganglia
A1
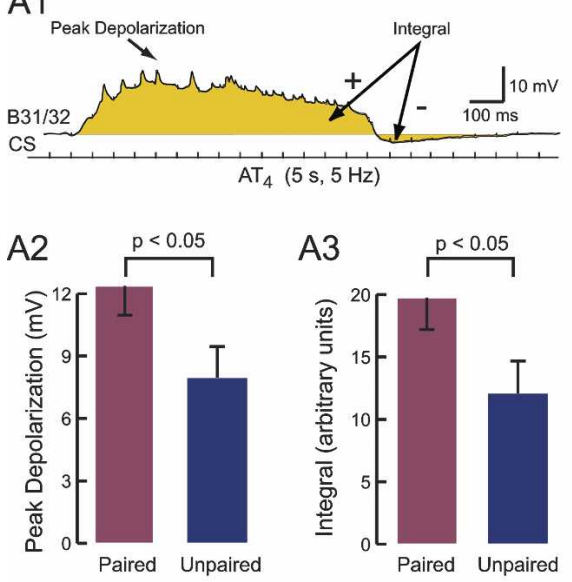

B1

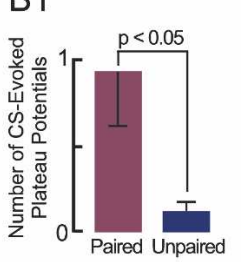

B
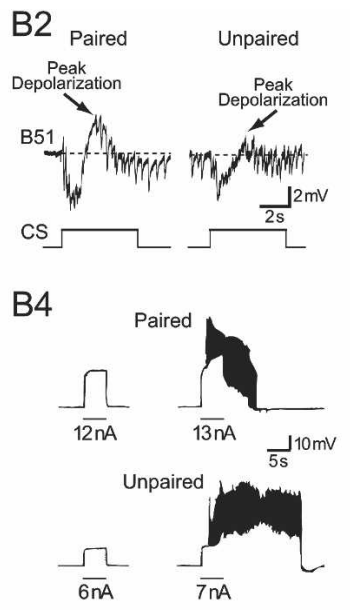

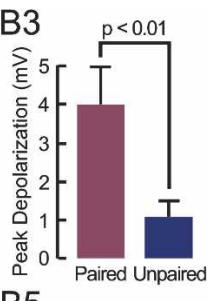

B5

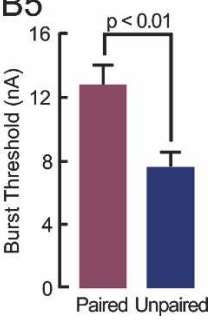

Figure 4. Correlates of classical conditioning in B31/32 and B51. Cerebral and buccal ganglia were removed from animals that received either paired or unpaired training. Intracellular recordings began $1-6 \mathrm{~h}$ following training and testing. Electrical stimulation of the $\mathrm{AT}_{4} \mathrm{nerve}(5 \mathrm{sec} ; 5 \mathrm{~Hz})$ was used as an in vitro analog of the CS. (A) Correlates in neurons B31/32. (A1) Stimulation of $\mathrm{AT}_{4}$ elicited a complex postsynaptic potential (CPSP) in B31/32. To quantify this CPSP, B31/32 was hyperpolarized to $-80 \mathrm{mV}$ and the peak depolarization and the integral (shaded region) of the CPSP were determined. To calculate the net excitatory component of the CPSP, negative integrals (i.e., hyperpolarizations; - symbol) were subtracted from the depolarizing component (+ symbol) of the CPSP. (A2) The average peak depolarization of the CPSP was significantly larger following paired training. (A3) The average net excitation also was significantly larger following paired training. (B) Correlates in neuron B51. (B1) While B51 was current-clamped to - $60 \mathrm{mV}$, the in vitro analog of the $\mathrm{CS}\left(5 \mathrm{sec}, 5 \mathrm{~Hz}\right.$ stimulation of $\mathrm{AT}_{4}$ ) elicited a significantly greater number of plateau potentials in B51 in ganglia from animals that received paired training as compared to animals that received unpaired training. (B2) B51 was current-clamped to $-60 \mathrm{mV}$ and stimulation of $A T_{4}$ elicited a CPSP. The peak depolarization of the CPSP was measured in B51 following paired and unpaired training. (B3) The average peak depolarization was significantly larger following paired training. (B4) While B51 was current-clamped at $-60 \mathrm{mV}$, the threshold for eliciting a plateau potential was determined by injecting brief $(5 \mathrm{sec})$, depolarizing current pulses of increasing amplitude. The threshold for eliciting a plateau potential in B51 was determined following paired and unpaired training. (B5) The threshold for eliciting a plateau potential in B51 was increased significantly following paired training. (Modified with permission from The Society for Neuroscience @ 2000, Lechner et al. 2000b, and from Nature Publishing Group @ 2006, Lorenzetti et al. 2006b [http://www.nature.com/].)

\section{Learning \& Memory}

www.learnmem.org 
taken from animals that received paired training as compared to preparations from animals that received unpaired training. These results indicate that classical conditioning of feeding behavior does not appear to affect the intrinsic properties of $\mathrm{B} 31 / 32$, but does enhance the excitation of B31/32 that is evoked by stimulation of $\mathrm{AT}_{4}$, which in turn may underlie the increased number of CS-elicited ingestion-like BMPs in vitro and the increased number of bites in vivo.

Because B51 plays a key role in expression of ingestion-like BMPs (Nargeot et al. 1999a,b), we also investigated whether conditioning altered the activity and/or intrinsic properties of B51 (Fig. 4B; Lorenzetti et al. 2006b). In preparations taken from animals that previously received paired training, stimulation of the $\mathrm{AT}_{4}$ nerve evoked a significantly greater number of plateau potentials in B51 as compared to preparations from animals that previously had received unpaired training (Fig. 4B1). The occurrence of plateau potentials in B51 is closely related to the expression of ingestion-like BMPs (Nargeot et al. 1999a,b). Neither the input resistance nor resting membrane potential of B51 were affected by classical conditioning. In contrast, paired training significantly increased the excitation of 51 that is elicited by stimulating the CS pathway (Fig. 4B2). The peak depolarization of the $\mathrm{AT}_{4}$-evoked cPSP in $\mathrm{B} 51$ was greater in ganglia taken from animals that received paired training as compared to preparations from animals that received unpaired training (Fig. 4B3). In addition, paired training produced a significant increase in the threshold for eliciting a plateau potential in B51 (Fig. 4B4,B5). Despite this increase in the threshold for eliciting activity in B51, however, as noted above, the CS elicited more plateau potentials in B51 following paired training. These results suggest that the other factors within the neural circuit (e.g., increased CSmediated excitation) must overcome the diminished excitability and elicit greater activity in B51, which results in a greater number of ingestion-like BMPs and, in turn, an increased number of bites in the intact animal following classical conditioning. The functional consequences of the increased threshold in B51 following paired training is unclear.

In summary, these data provide initial insights into the organization of the CS and US pathways supporting appetitive classical conditioning. Biting behavior is produced by a response system that comprises command-like neurons (e.g., CBIs) in the cerebral ganglion and CPG neurons (e.g., B31/32 and B51) in buccal ganglia. Mechanoafferents that innervate the lips mediate the CS. The US is mediated by a sensory pathway from the foregut, which, when paired with the CS, is able to modulate the CS pathway and the intrinsic properties of some elements of the circuit.

\section{Appetitive operant conditioning}

Brembs et al. (2002) developed a behavioral protocol for reward operant conditioning of feeding behavior in Aplysia that produces both short- and long-term memory. The in vivo protocol was developed using the consummatory phase of feeding (i.e., biting) as the operant. The first step was to design a suitable reinforcement (i.e., reward). Previous studies indicated that the anterior branch of the esophageal nerve $\left(\mathrm{En}_{2}\right)$ plays an important role in learning-induced modifica- tions of feeding in Aplysia. For example, the $\mathrm{En}_{2}$ appears to mediate the US in appetitive classical conditioning (see above; Lechner et al. 2000a) and the $\mathrm{En}_{2}$ can function as reinforcement in an in vitro analog of operant conditioning (see below; Nargeot et al. 1997). Moreover, bouts of high-frequency neural activity ( $\sim 3 \mathrm{sec}$, $\sim 30 \mathrm{~Hz}$ ) were recorded in vivo during the ingestion of food, whereas very little activity was recorded from $\mathrm{En}_{2}$ during biting in the absence of food (Brembs et al. 2002).

Based upon these data, an in vivo operant conditioning protocol was developed in which stimulation of the $\mathrm{En}_{2}$ was used as reinforcement. One day prior to training, animals were implanted with a stimulating electrode on the $\mathrm{En}_{2}$ (Fig. 5A). During training and testing, animals were allowed to move freely and an observer noted the occurrence of all bites. During contingent training, bites were immediately followed by reinforcements (brief stimulation of $\mathrm{En}_{2}$ ) (Fig. 5B). During yoke training, animals received the same pattern and number of reinforcements, but these reinforcements were not correlated with the behavior of the animal (Fig. 5B). Pilot studies determined the intensity of the stimulus to be 8 VDC ( $10 \mathrm{msec}$ pulses, $30 \mathrm{~Hz}, 3 \mathrm{sec})$. At this intensity no overt behavioral response could be observed. Conditioning was measured as the number of bites that occurred during a 5-min post-test observation period. The post-test observations occurred either immediately following training or $24 \mathrm{~h}$ after training. Both immediately (Fig. 6A) and $24 \mathrm{~h}$ (Fig. 6B) after a 10 -min training session, animals in the contingent reinforcement group produced more bites than animals in the yokedcontrol group. Thus, brief stimulation of the $\mathrm{En}_{2}$ can function as reinforcement during operant conditioning of feeding, and 10 min of training is sufficient to induce both short- and long-term memory.

\section{Neural correlates of in vivo operant conditioning}

The initial search for neural correlates of operant conditioning focused on B51, a cell that plays a key role in the production of ingestion-like BMPs (Nargeot et al. 1999a) and that also is a site
A

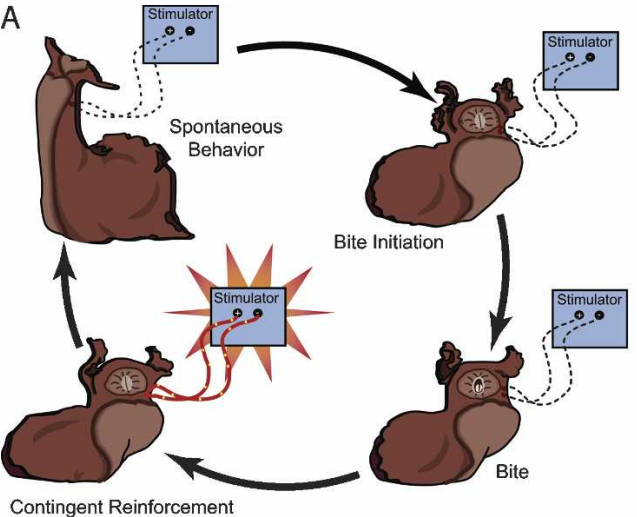

B

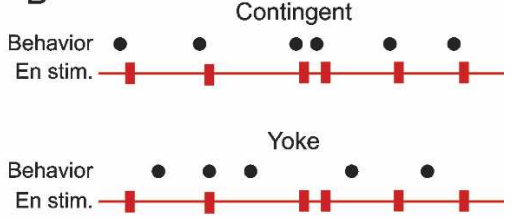

Figure 5. Operant conditioning of feeding behavior in vivo. $(A)$ One day prior to training, animals were implanted with a stimulating electrode on the anterior branch of left esophageal nerve. During the training and testing phases of an experiment, the animal was allowed to move freely in a small aquarium. The aquarium contained fresh artificial seawater and a dilute extract of seawater, which helped to induce feeding behavior. An observer noted the occurrence of all bites. The observer could also deliver brief electrical shocks to the En (see panel $B$ ). (B) The black dots that are labeled Behavior represent the occurrence of a bite. The red boxes that are labeled En stim. represent the occurrence of a reinforcement (i.e., electrical stimulation of En). During contingent training, bites were immediately followed by reinforcements. During yoke training, animals received the same pattern and number of reinforcements, but these reinforcements were not correlated with the behavior of the animal. Conditioning was measured as the number of bites that occurred during a 5-min post-test observation period. The post-test observations occurred either immediately following training or $24 \mathrm{~h}$ after training. (Modified with permission from AAAS (c) 2002, Brembs et al. 2002, and from The Society for Neuroscience (c) 1997, Nargeot et al. 1997.) 
A. Immediately after training

\section{B. $24 \mathrm{~h}$ after training}
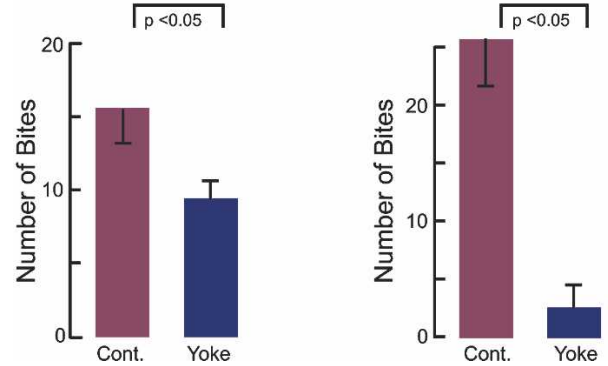

Figure 6. Short- and long-term memory following operant conditioning of feeding behavior. (A) A significantly greater number of bites were observed immediately following training with contingent reinforcement (Cont.) as compared to the yoke training. (B) In a separate group of animals, the retention for operant conditioning was measured $24 \mathrm{~h}$ after training. A significantly greater number of bites were observed $24 \mathrm{~h}$ after training with contingent reinforcement as compared to the yoke training (Modified with permission from AAAS $\odot$ 2002, Brembs et al. 2002.)

of plasticity following classical conditioning (see above; Lorenzetti et al. 2006b). Within 1-2 h after training, the buccal ganglia were removed and the resting membrane potential, input resistance, and burst threshold of B51 were measured. B51 had a significantly lower burst threshold (Fig. 7A) and a significantly higher input resistance (Fig. 7B) in ganglia from animals that had received contingent reinforcement as compared to ganglia from animals in the yoked-control group. There was no difference in resting membrane potential between the two groups. An increase in input resistance and a decrease in threshold would increase the probability of B51 becoming active and, thus, would increase the number of ingestion-like BMPs that are expressed by the feeding circuitry. These predictions have been confirmed using an in vitro analog of operant conditioning (see below).

It is important to note that B51 is a site of plasticity following both classical and operant conditioning, but that the two training protocols produce very different changes in B51. Classical conditioning increases the threshold for eliciting a plateau potential in B51, whereas operant conditioning decreases the threshold. Moreover, operant conditioning increases the input resistance of B51, whereas classical conditioning does not affect the input resistance. These results suggest that in some respects classical and operant are mediated by fundamentally different cellular processes.

\section{In vitro analogs of classical and operant conditioning}

The development and validation of in vitro analogs is an important step in studies of the cellular and molecular mechanisms underlying associative learning. Such preparations will allow for the analyses of modifications in the intrinsic properties and/or synaptic strengths of identified elements during and following associative learning.

\section{In vitro analog of classical conditioning}

To further characterize the cellular processes involved in classical conditioning of feeding behavior, an in vitro analog of classical conditioning was developed (Mozzachiodi et al. 2003). The preparation consisted of cerebral and buccal ganglia, which were isolated from naive animals. The isolated nervous system was trained using extracellular stimulation of peripheral nerves. Stimulation of $\mathrm{AT}_{4}$ and $\mathrm{En}_{2}$ were used to activate the CS and US pathways, respectively. Generally, paired and unpaired protocols were used. The number of training trials, the ITI, and the ISI of the in vitro training protocol were selected to be similar to those used by Lechner et al. (2000a) during in vivo behavioral training.

The effects of training were assessed by subtracting the number of BMPs elicited by the pre-test CSs from the number elicited by the post-test CSs. Ganglia that received paired training had a significantly larger increase in the number of CS-evoked BMPs than the unpaired-control groups (Mozzachiodi et al. 2003; Lorenzetti et al. 2006b). There was no significant change in the frequency of spontaneous BMPs in either group. These results indicate that the paired CS/US presentations in the in vitro ana$\log$ specifically increased the ability of the CS to evoke BMPs and that the in vitro training strengthened the CS-mediated pathway selectively, without affecting the spontaneous activity of the CPG.

Additional analysis of the types of BMPs evoked by CS (i.e., stimulation of $\mathrm{AT}_{4}$ ) revealed that the increase was almost exclusively attributable to an increase in the number of ingestion-like BMPs (Mozzachiodi et al. 2003). Importantly, this increase in the number of CS-evoked ingestion-like BMPs is similar to the neural correlate produced by classical conditioning in vivo (Lechner et al. 2000b) and closely resembles the effect of behavioral training on the number of bites (Lechner et al. 2000a). Together, these
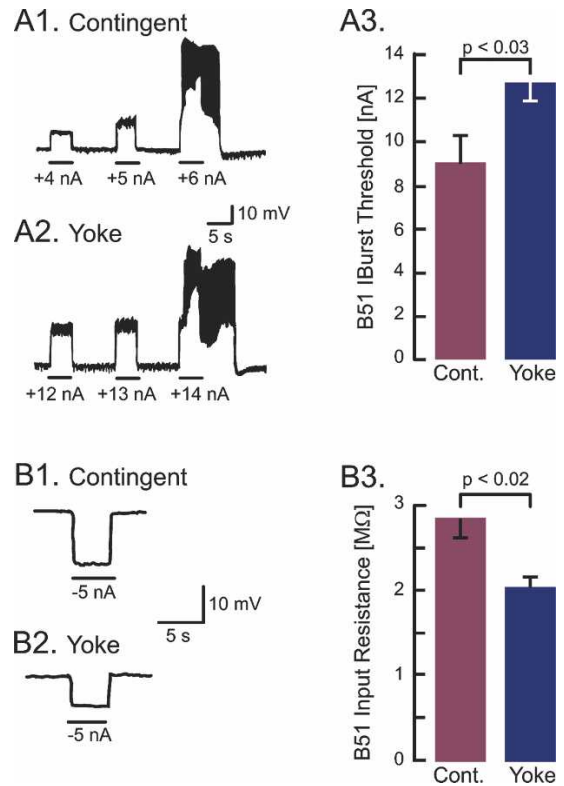

Figure 7. Correlates of operant conditioning in B51. Buccal ganglia were removed from animals that were trained with either contingent reinforcement or from animals that received the yoke training. Intracellular records began $\sim 1.5 \mathrm{~h}$ following training and testing. B51 was current-clamped to $-60 \mathrm{mV}$ for the duration of the experiment. $(A)$ Burst threshold. $(A 1, A 2)$ Intracellular recordings from B51 cells from a matched pair of contingently reinforced and yoked-control animals. Depolarizing current pulses were injected into each B51 until the cell generated a plateau potential. In this example, a 6-nA current pulse was sufficient to generate a plateau potential in B51 from a contingently reinforced animal $(A 1)$, whereas $14 \mathrm{nA}$ were required to generate a plateau potential in B51 from the corresponding yoked-control animal (A2). (A3) Summary data. B51 cells from the contingent reinforcement group required significantly less current to elicit the plateau potential. $(B)$ Input resistance. $(B 1, B 2)$ Intracellular recordings from B51 cells from both contingently reinforced and yoked-control animals. Hyperpolarizing current pulses were injected into B51 and the input resistance of the cell was measured. In this example, the membrane potential of B51 from a contingently trained animal (B1) deflected more in response to the current pulse than the potential of B51 from a yoked-control animal (B2). (B3) Summary data. B51 input resistance was significantly increased in contingently reinforced animals. (Modified with permission from AAAS (c) 2002, Brembs et al. 2002.)

\section{Learning \& Memory}


results indicate that paired stimulation of peripheral nerves in vitro induces pairing-specific changes in the neural circuitry that mediates feeding behavior and that these changes persist for at least $1 \mathrm{~h}$ following training. Moreover, the changes produced in vitro are analogous to the effects of in vivo training.

\section{Neural changes induced by the in vitro analog of classical conditioning}

Additional investigations examined changes in the CS-mediated synaptic input to neurons B31/32 following in vitro training protocols. The peak amplitude and area of the CS-evoked cPSP in B31/32 were monitored before (pre-test) and $60 \mathrm{~min}$ after (posttest) training. The amplitude and area of the cPSP before training did not differ between the paired and unpaired groups. After paired training, however, the observed increase in the peak amplitude and the area of CS-evoked cPSP in B31/32 were significantly greater than similar measurements in preparations that received unpaired training. In contrast, the intrinsic properties of B31/32 (i.e., resting membrane potential and input resistance) did not change in either group. Paired training also produced changes in B51. Following paired training the number of CSevoked plateau potentials in B51 was significantly increased, the peak depolarization of the CS-evoked cPSP in B51 was significantly increased, and the threshold for eliciting a plateau potential was significantly increased, but the resting membrane potential and input resistance were unaffected (Lorenzetti et al. 2006b). Once again, it is important to note that these results are similar to those following in vivo conditioning (see above), which suggests that both in vitro and in vivo conditioning produce similar changes in the neural circuitry that mediates feeding.

The in vitro analog is being used to extend the analysis of classical conditioning, in part, by investigating additional sites of plasticity (Mozzachiodi et al. 2003). Two sites were examined that failed to exhibit changes following conditioning: neurons B4/5 and CBI-2 (Mozzachiodi et al. 2003; see also Lechner et al. 2000b). One additional site of plasticity was found, however. Paired training enhances the CS-evoked input to the commandlike neuron CBI-2 (Fig. 1), which leads to increased CS-evoked spike activity in CBI-2. This pairing-specific increase in the spike activity in CBI-2 may, in turn, contribute to the increased excitation in B31/32 following paired training (see Fig. 4A).

\section{Analyzing the reinforcement pathway}

Lesions of the En block classical conditioning, which suggests that the En mediates the effects of the US during appetitive classical conditioning (Lechner et al. 2000a). Moreover, histofluorenscence analysis indicates that processes within the En contain dopamine (DA) (Kabotyanski et al. 1998), which suggests that DA may be a transmitter underlying the associative plasticity following classical conditioning. A number of studies in both vertebrates and invertebrates suggest that DA may play a critical role in the reinforcement pathway during various forms of associative learning (for reviews, see Berke and Hyman 2000; Kelley and Berridge 2002; Schultz 2002; Jay 2003; Harley 2004; Wise 2004). To analyze the role of DA in appetitive classical conditioning, we investigated the effects of a DA receptor antagonist, methylergonovine (e.g., Teyke et al. 1993; Nargeot et al. 1999c), on the acquisition of pairing-specific changes in the in vitro analog of classical conditioning (Reyes et al. 2005). Four groups of preparations were compared: Two received paired training, one with (1 $\mathrm{nM}$ ) and the other without methylergonovine, and two received unpaired training, one with and the other without methylergonovine. The change in the number of ingestion-like BMPs during a 10-min test period $1 \mathrm{~h}$ after training was calculated (post-test minus pre-test). Confirming previous results (Mozzachiodi et al. 2003), in control saline, the number of BMPs was significantly larger in the preparations that received paired training group as compared to the unpaired training protocol. In contrast, in the presence of methylergonovine, paired training had no effect on the number of BMPs. Thus, the behavioral, histofluorenscence, and pharmacological data are consistent with the hypothesis that DA within the En mediates the actions of the US during classical conditioning.

In summary, these data indicate that a reduced preparation of the cerebral and buccal ganglia can be classically conditioned in vitro by pairing stimulation of peripheral nerves (i.e., $\mathrm{AT}_{4}$ and $\mathrm{En}_{2}$ ), which are used to mimic the CS and US, respectively. In naive preparations, weak stimulation of $\mathrm{AT}_{4}$ (i.e., the CS) has a low probability of eliciting patterned activity in the CPG, whereas stimulation of $\mathrm{En}_{2}$ (i.e., the US) is able to drive BMPs. The memory for classical conditioning appears to be distributed among select elements of the feeding neural network. Some elements remain unaffected (e.g., B4/5, CBI-2), whereas other elements are sites of plasticity. For example, paired training results in an enhancement of the CS-induced excitation of CBI-2, B31/ 32 , and B51 due to modification of synaptic connections and/or intrinsic properties of neurons along the CS pathway. Thus, the CS becomes more effective in eliciting plateau potentials in B51, despite an increase in the threshold of B51, and thereby elicits more ingestion-like BMPs, which may underlie the observed increase number of bites following in vivo classical conditioning. Finally, DA appears to be a transmitter that mediates the US.

\section{In vitro analog of operant conditioning}

An in vitro analog of operant conditioning was developed (Nargeot et al. 1997; Brembs et al. 2004) and it was used to extend the investigations into the cellular mechanisms of operant conditioning. Generally, the in vitro analog preparation consisted of buccal ganglia isolated from naive animals (however, see Brembs et al. 2004). Sustained rhythmic activity (i.e., BMPs) was elicited by tonic, low-frequency stimulation of a peripheral buccal nerve $(\mathrm{n} 2,3)$. During a 10-min training period, each ingestion-like BMP was reinforced by brief stimulation of $\mathrm{En}_{2}$ (i.e., contingent reinforcement group). Generally, the control consisted of a yokedcontrol group, which received noncontingent presentations of $\mathrm{En}_{2}$ stimulation. Immediately following contingent reinforcement, preparations that received contingent reinforcement produced significantly more BMPs than the yoked-control group (Nargeot et al. 1997; Brembs et al. 2004). This increase persisted for at least $24 \mathrm{~h}$ after the 10-min training period (Nargeot et al. 1999c; Mozzachiodi et al. 2006). Importantly, the increase in expression of BMPs was accounted for by an increase in the number of ingestion-like BMPs that were produced, i.e., the type of BMPs that was contingently reinforced.

\section{Neural changes induced by the in vitro analog of operant conditioning}

B51 is selectively associated with ingestion-like BMPs (Nargeot et al. 1999a,b) and B51 is a site of plasticity following in vivo operant conditioning (Brembs et al. 2002). Nargeot et al. (1999a,b) investigated whether the activity and/or properties of B51 (i.e., burst threshold and input resistance) were modified by contingent reinforcement. In preparations that received contingent reinforcement, the number of plateau potentials in B51 was increased significantly and the burst threshold in B51 was decreased significantly as compared to yoke controls. In addition, the input resistance of B51 was increased significantly following contingent reinforcement as compared to yoke controls. These changes could be induced by an explicit association of reinforcement with depolarization of B51. Importantly, these modifications were similar to those induced by the in vivo behavioral conditioning (see above). Taken together, these results indicate 
that contingent reinforcement of ingestion-like BMPs modified the intrinsic properties of B51, which, in turn, may contribute to the increased expression of ingestion-like BMPs.

\section{Analyzing the reinforcement pathway}

During operant conditioning in vivo, electrical stimulation of the En served as the reinforcement and the En is rich in DAcontaining processes (see above), which suggest that DA mediates reinforcement during operant conditioning. To analyze the role of DA in operant conditioning, the in vitro analog of operant conditioning was used to investigate the effects methylergonovine had on the changes induced by contingent reinforcement (Nargeot et al. 1999c). Four groups of preparations were compared: two contingent reinforcement groups, one with $(1 \mathrm{nM})$ and the other without methylergonovine, and two yoked-control groups, one with and the other without methylergonovine. The number of ingestion-like BMPs during a 10-min test period $1 \mathrm{~h}$ after training was counted. Confirming previous results (Nargeot et al. 1997), in control saline, the number of ingestion-like BMPs was significantly larger in the contingent reinforcement group as compared to the yoked-control group. In contrast, in the presence of methylergonovine, contingent reinforcement had no effect on the number of ingestion-like BMPs. These results are consistent with the hypothesis that DA is a transmitter that mediates both the US during classical conditioning (see above) and the contingent reinforcement during operant conditioning.

\section{Single-cell analog of operant conditioning}

The studies described above indicate that changes in the intrinsic properties of B51 are correlated with contingent reinforcement. The cellular mechanisms that underlie this associative plasticity may be intrinsic to B51 or may be due to extrinsic factors. For example, the associative plasticity may occur in some other cell, which in turn exerts a tonic influence on B51. To address this issue, a single-cell analog of the operant conditioning was developed (Brembs et al. 2002). In this analog, individual B51 neurons were isolated from naive animals and maintained in culture. Because DA appears to play a critical role in the reinforcement pathway (see above; Nargeot et al. 1999c), reinforcement was mimicked by a brief ionotophoretic puff of DA onto the neuron. Since B51 exhibits a plateau potential during ingestion-like BMPs, DA reinforcement was made contingent upon a plateau potential in the cell that was elicited by a brief depolarizing current pulse.

Two groups of cells were examined: a group that received contingent reinforcement and a control group that received noncontingent reinforcement. In the contingent reinforcement group, the cells received seven depolarizations over a 10-min training period. Each of these depolarizations elicited a plateau potential in B51, which was immediately followed by a brief (6 sec) iontophoretic puff of DA. In the control group, cells also received seven depolarizations and DA puffs, but the DA puff occurred $40 \mathrm{sec}$ after the plateau potential. Contingent reinforcement produced a significant decrease in the burst threshold and a significant increase in the input resistance as compared to cells in the control group (Fig. 8). The changes produced in B51 by the single-cell analog of operant conditioning are similar to those produced by both the in vitro analog (Nargeot et al. 1999b) and in vivo training (Brembs et al. 2002). These data indicate that mechanisms intrinsic to B51 are responsible for both induction and maintenance of the biophysical changes associated with reward operant conditioning. In addition, the results suggest that aspects of operant conditioning and DA-mediated reward can be reconstituted and analyzed in single-cultured neurons.

Studies with the single-cell analog are providing some initial insights to the biochemical processes that may mediate the induction of operant conditioning (Lorenzetti et al. 2006a). The
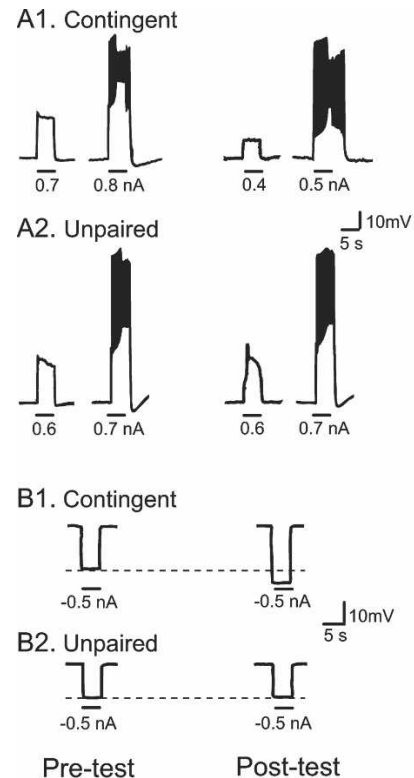
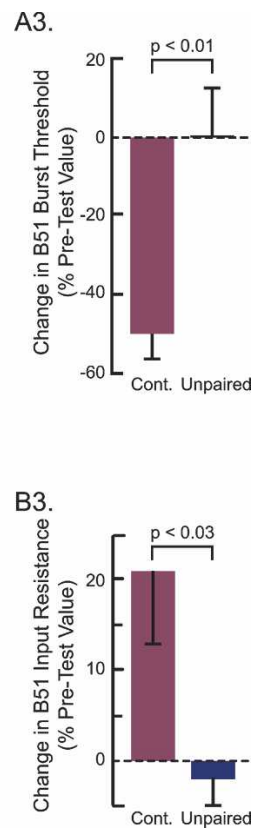

Figure 8. Changes in $\mathrm{B} 51$ produced by single-cell analog of operant conditioning. (A) Burst threshold. $(A 1, A 2)$ Intracellular recordings from a pair of contingently reinforced and unpaired neurons. Depolarizing current pulses were injected into B51 before (pre-test) and after (post-test) training. In this example, contingent reinforcement led to a decrease in burst threshold from 0.8 to $0.5 \mathrm{nA}(A 1)$, whereas it remained at $0.7 \mathrm{nA}$ in the corresponding unpaired cell (A2). (A3) Summary data. The burst threshold was decreased significantly in cells that received contingent reinforcement training. $(B)$ Input resistance. $(B 1, B 2)$ Intracellular recordings from a pair of contingently reinforced and unpaired control neurons. Hyperpolarizing current pulses were injected into B51 before (pre-test) and after (post-test) training. In this example, contingent reinforcement led to an increased deflection of the B51 membrane potential in response to the current pulse $(B 1)$, whereas the deflection remained constant in the corresponding unpaired cell (B2). (B3) Summary data. The input resistance was increased significantly in the cell that received contingent reinforcement training. (Modified with permission from AAAS (C) 2002, Brembs et al. 2002.)

cAMP/PKA pathway appears to be involved. D1-like receptors, which are likely to be coupled to adenylyl cyclase, were identified on the membrane of B51. Moreover, inhibiting PKA with bath application of Rp-cAMP blocked conditioning. Conversely, injecting cAMP into B51 mimicked conditioning. Blocking PKC with bath application of bisindolylmaleimide also blocked conditioning. Thus, both PKA and PKC are necessary for conditioning. Because activating the PKA pathway alone can fully mimic conditioning, it appears that PKC is acting upstream of PKA and suggests that the point of convergence may be adenylyl cyclase.

These analyses of B51 also suggest that intrinsic cell-wide plasticity may contribute to appetitive operant conditioning. Moreover, the results suggest a possible general mechanism for operant conditioning. When activity in a neuron is followed by a reinforcing modulatory transmitter, biochemical and biophysical changes are induced in that neuron, which lead to an increased probability of subsequent activity in that neuron and, once activated, a more prolonged response. It is intriguing to note that similar results were observed in another in vitro analog of operant conditioning that utilized hippocampal slices (Stein and Belluzzi 1989; Stein et al. 1993) where contingent puffing of DA enhanced bursting activity in CA1 pyramidal cells. Although B51 is a key element of the neural circuit underlying feeding behavior in Aplysia, given the number of neurons in the buccal CPG, it is likely that B51 is not the only site of plasticity during 
operant conditioning (nor is cell-wide plasticity likely to be the only mechanism). Thus, it will be important to expand the investigation of sites and mechanisms of plasticity that may underlie operant conditioning.

\section{Conclusions}

Feeding behaviors of a variety of gastropod mollusks can be modified by associative learning paradigms (e.g., Gelperin 1975; Croll and Chase 1977; Davis 1982; Davis et al. 1983; Susswein and Schwartz 1983; Alexander et al. 1984; Gelperin and Culligan 1984; Maximova and Balaban 1984; Mpitsos and Cohan 1986a,b; Susswein et al. 1986; Hopfield and Gelperin 1989; Kemenes and Benjamin 1989; Sahley et al. 1990; Kemenes and Benjamin 1994; Nikitin 1994; Nikitin et al. 1994; Colwill et al. 1997; Kojima et al. 1997; Benjamin et al. 2000; Jones et al. 2001; Kojima et al. 2001; Elliott and Susswein 2002; Lorenzetti and Byrne 2002; Brembs $2003 a, b)$. Learning in these gastropods has many features similar to learning in vertebrates. It can occur rapidly, and the memories following learning can persist for long periods of time. In many of these preparations, the properties of identified neurons and networks that participate in the feeding behavior are amenable to cellular analysis and the relevant features of the neuronal activity and learning are readily expressed in vitro (e.g., Kemenes et al. 2006; Straub et al. 2006). Thus, studies of learning in gastropods offer an opportunity to determine the cellular mechanisms and to gain key insights into processes that may also contribute to learning in vertebrates, including man.

The feeding system of Aplysia is providing new insights into the neural networks and subcellular mechanisms that mediate two important forms of associative learning (i.e., classical and operant conditioning), as well as providing information regarding the mechanistic inter-relationships between them. Moreover, mechanistic information on conditioning of feeding will provide insights into strategies used by the nervous system to encode and store associations. Only a few examples of associative conditioning have been analyzed mechanistically so far (for reviews, see Carew and Sahley 1986; Byrne 1987; Abrams and Kandel 1988; Crow 1988; Sahley 1995; Benjamin et al. 2000; Burrell and Sahley 2001; Christian and Thompson 2003; Crow 2004; Robleto et al. 2004; Fanselow and Poulos 2005; Maren 2005; Kim and Jung 2006). Other examples would help identify the general principles of organization among them.

Some interesting similarities and differences between appetitive classical and operant conditioning have been identified (Table 1). One similarity is the nature of the reinforcement pathway and its transmitter. The En is the reinforcement pathway for operant conditioning and the US pathway for classical conditioning. This pathway appears to use DA as a transmitter. Also, the direct application of DA can mimic the reinforcement. These results are consistent with the view that DA can mediate the US/reinforcement for appetitive forms of both classical and op-

Table 1. Comparison of classical and operant conditioning

\begin{tabular}{lll}
\hline & $\begin{array}{c}\text { Classical } \\
\text { conditioning }\end{array}$ & $\begin{array}{c}\text { Operant } \\
\text { conditioning }\end{array}$ \\
\hline Number of bites & Increase & Increase \\
Number of ingestion-like BMPs & Increase & Increase \\
Reinforcement pathway & En & En \\
Reinforcement transmitter & Dopamine & Dopamine \\
Number of plateau potentials in B51 & Increase & Increase \\
Resting membrane potential of B51 & No change & No change \\
Input resistance of B51 & No change & Increase \\
Burst threshold of B51 & Increase & Decrease \\
\hline
\end{tabular}

(Modified with permission from Nature Publishing Group @ 2006, Lorenzetti et al. 2006b [http://www.nature.com/].)
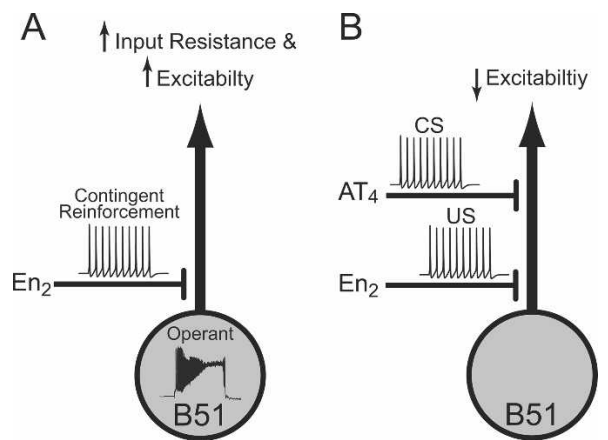

Figure 9. Schematic diagram of the different contingencies during operant $(A)$ vs. classical $(B)$ conditioning. The occurrence of a plateau potential in cell B51 is believed to be critical for the production of ingestionlike BMPs (Nargeot et al. 1999a,b) and presumably for feeding in freely behaving animals. Thus, the occurrence of an ingestion-like BMP and/or a plateau potential in B51 were the neuronal equivalents of an operant and were immediately followed by stimulation of the anterior branch of the esophageal nerve $\left(E n_{2}\right)$. As a result of this contingent reinforcement, the input resistance and excitability of B51 were increased (upward arrows). Presumably, the changes in B51 were induced by an interaction between some trace of the activity in B51 (e.g., calcium influx during the plateau potential) and some DA-induced process (e.g., activation of adenylyl cyclase). During classical conditioning, the contingence was between stimulation of $\mathrm{AT}_{4}$ (the CS) and $\mathrm{En}_{2}$ (the US). As a result of this pairing, the excitability of B51 decreased (downward arrow). Presumably, the changes in B51 were induced by an interaction between a process induced by a yet-to-be-identified transmitter released during the CS and a DA-induced process. Despite the opposite effects that classical and operant conditioning had on the excitability of B51, both protocols increased the number of plateau potentials, the number of ingestion-like BMPs, and the number of bites following conditioning. Thus, some other modifications (e.g., increased synaptic input) must override the decreased excitability of B51 following classical conditioning.

erant conditioning. B51 is a cellular locus for the changes induced by both operant and classical conditioning. Both in vivo and in vitro operant conditioning increase the input resistance and the excitability of B51. These two changes make B51 more likely to be active, which can account for the increased expression of ingestive behavior following contingent reinforcement. In contrast, no pairing-specific changes in the input resistance of B51 were observed following either in vivo or in vitro classical conditioning. Also, both operant and classical conditioning modified the threshold level for eliciting plateau potentials in neuron B51, but in opposite directions, revealing a fundamental difference in the cellular mechanisms underlying these two forms of associative learning.

B51 appears to be a coincidence detector for both the CS-US association (classical conditioning) and the contingency between ingestive behavior and reinforcement (operant conditioning) (Fig. 9). Because DA likely mediates both the US and the reinforcement, a key problem is to elucidate the mechanisms that lead to the induction of opposite effects on the burst threshold. One possibility is that the coincidence detector for classical conditioning involves an association between a transmitter released by the CS and DA (Fig. 9B), whereas, for operant conditioning, the coincidence detector involves an association between the cellular effects of plateau potentials in B51 and DA (Fig. 9A). Exploring these pathways and their interactions will provide important insights into the molecular logic of operant conditioning and classical conditioning.

The finding that DA is involved in both appetitive classical conditioning and reward operant conditioning supports current theories that DA signals encode the value and probability of reward (for reviews, see Schultz 2002; Jay 2003; Chinta and Andersen 2005; Harley 2004; Kelley 2004; Hyman 2005; Tobler et 
al. 2005; Wise 2005). Dopamine plays a critical role in associative learning in mammals (Schultz 1997; Liu et al. 2004; Wise 2004). Pharmacological blockade of DA receptors interferes with the acquisition of conditioned behaviors produced by classical and operant conditioning procedures (Schultz 1997; Eyny and Horvitz 2003; Andrzejewski et al. 2005), and reinforcing stimuli activate DAergic neurons (Shizgal and Murray 1989; Schultz 2001). Moreover, the activity of DAergic neurons is correlated with changes in the parameters of reinforcing stimuli such as probability, uncertainty, and magnitude (Cromwell and Schultz 2003; Fiorillo et al. 2003; Martin-Soelch et al. 2003; Montague et al. 2004; Stefani and Moghaddam 2006) and stimulation of DAergic systems can serve as reward (Wise 2005). Dopamine appears to play a similarly important role in associative learning in Aplysia, and feeding behavior of Aplysia provides a useful model system for future studies of cellular and molecular mechanisms of DA-mediated reinforcement.

\section{Acknowledgments}

We thank Dr. R. Mozzachiodi for his comments on an earlier draft of the manuscript. Supported by NIMH research grant R01MH 58321.

\section{References}

Abrams, T.W. and Kandel, E.R. 1988. Is contiguity detection in classical conditioning a system or a cellular property? Learning in Aplysia suggests a possible molecular site. Trends Neurosci. 11: 128-135.

Alexander, J., Audesirk, T.E., and Audesirk, G.J. 1984. One-trial reward learning in the snail Lymnea stagnalis. J. Neurobiol. 15: 67-72.

Andrzejewski, M.E., Spencer, R.C., and Kelley, A.E. 2005. Instrumental learning, but not performance, requires dopamine D1-receptor activation in the amygdala. Neuroscience 135: 335-345.

Benjamin, P.R., Staras, K., and Kemenes, G. 2000. A systems approach to the cellular analysis of associative learning in the pond snail Lymnaea. Learn. Mem. 7: 124-131.

Berke, J. and Hyman, S. 2000. Addiction, dopamine, and the molecular mechanisms of memory. Neuron 25: 515-532.

Botzer, D., Markovich, S., and Susswein, A. 1998. Multiple memory processes following training that a food is inedible in Aplysia. Learn. Mem. 5: 204-219.

Brembs, B. 2003a. Operant conditioning in invertebrates. Curr. Opin. Neurobiol. 13: 710-717.

Brembs, B. 2003b. Operant reward learning in Aplysia. Curr. Dir. Psychol. Sci. 12: 218-221.

Brembs, B., Lorenzetti, F., Reyes, F., Baxter, D.A., and Byrne, J.H. 2002. Operant reward learning in Aplysia: Neuronal correlates and mechanisms. Science 296: 1706-1709.

Brembs, B., Baxter, D.A., and Byrne, J.H. 2004. Extending in vitro conditioning in Aplysia to analyze operant and classical processes in the same preparation. Learn. Mem. 11: 412-421.

Burrell, B.D. and Sahley, C.L. 2001. Learning in simple systems. Curr. Opin. Neurobiol. 11: 757-764.

Byrne, J.H. 1987. Cellular analysis of associative learning. Physiol. Rev. 67: $329-439$.

Carew, T.J. and Sahley, C.L. 1986. Invertebrate learning and memory: From behavior to molecules. Annu. Rev. Neurosci. 9: 435-487.

Chinta, S.J. and Andersen, J.K. 2005. Dopaminergic neuorns. Int. J. Biochem. Cell Biol. 37: 942-946.

Christian, K.M. and Thompson, R.F. 2003. Neural substrates of eyeblink conditioning: Acquisition and retention. Learn. Mem. 10: 427-455.

Church, P. and Lloyd, P. 1994. Activity of multiple identified motor neurons recorded intracellularly during evoked feeding like motor programs in Aplysia. J. Neurophysiol. 72: 1794-1809.

Colwill, R., Goodrum, K., and Martin, A. 1997. Pavlovian appetitive discriminative conditioning in Aplysia californica. Anim. Learn. Behav. 25: 268-276.

Croll, R.P. and Chase, R. 1977. A long-term memory for food odors in the land snail, Achatina fulica. Behav. Biol. 19: 261-268.

Cromwell, H.C. and Schultz, W. 2003. Effects of expectations for different reward magnitudes on neuronal activity in primate striatum. J. Neurophysiol. 89: 2823-2838.

Cropper, E.C., Evans, C.G., Hurwitz, I., Jing, J., Proekt, A., Romero, A., and Rosen, S.C. 2004. Feeding neural networks in the mollusc Aplysia. Neurosignals 13: 70-86.

Crow, T. 1988. Cellular and molecular analysis of associative learning and memory in Hermissenda. Trends Neurosci. 11: 136-147.
Crow, T. 2004. Pavlovian conditioning of Hermissenda: Current cellular, molecular, and circuit perspectives. Learn. Mem. 11: 229-238.

Davis, W.J. 1982. Neural consequences of experience in Pleurobranchaea californica. J. Physiol. (Paris) 78: 793-798.

Davis, W.J., Gillette, R., Kovac, M.P., Croll, R.P., and Matera, E.M. 1983. Organization of synaptic inputs to paracerebral feeding command interneurons of Pleurobranchaea californica. III. Modifications induced by experience. J. Neurophysiol. 49: 1557-1572.

Dembrow, N.C., Jing, J., Brezina, A., and Weiss, K.R. 2004. A specific synaptic pathway activates a conditional plateau potential underlying protraction phase in the Aplysia feeding central pattern generator. J. Neurosci. 24: 5230-5238.

Elliott, C. and Susswein, A. 2002. Comparative neuroethology of feeding control in molluscs. J. Exp. Biol. 205: 877-896.

Eyny, Y.S. and Horvitz, J.C. 2003. Opposing role of D1 and D2 receptor in appetitive conditioning. J. Neurosci. 23: 1584-1587.

Fanselow, M.S. and Poulos, A.M. 2005. The neuroscience of mammalian associative learning. Annu. Rev. Psychol. 56: 207-234.

Fiorillo, C.D., Tobler, P.N., and Schultz, W. 2003. Discrete coding of reward probability and uncertainty by dopamine neurons. Science 299: 1898-1902.

Gelperin, A. 1975. Rapid food-aversion learning by a terrestrial mollusk. Science 189: 567-570.

Gelperin, A. and Culligan, N. 1984. In vitro expression of in vivo learning by an isolated molluscan CNS. Brain Res. 304: 207-213.

Harley, C.W. 2004. Norepinephrine and dopamine as learning signals. Neural Plast. 11: 191-204.

Hopfield, J.F. and Gelperin, A. 1989. Differential conditioning to a compound stimulus and its components in the terrestrial mollusc Limax maximus. Behav. Neurosci. 103: 274-293.

Horn, C.C. and Kupfermann, I. 2002. Egestion feeding responses in Aplysia persist after sectioning of the cerebral-buccal connectives: Evidence for multiple sites of control of motor programs. Neurosci. Lett. 323: $175-178$.

Horn, C.C., Zhurov, Y., Orekhova, I.V., Proekt, A., Kupfermann, I., Weiss, K.R., and Brezina, V. 2004. Cycle-to-cycle variability of neuromuscular activity in Aplysia feeding behavior. J. Neurophysiol. 92: $157-180$.

Hurwitz, I., Goldstein, R., and Susswein, A.J. 1994. Compartmentalization of pattern-initiation and motor function in the B31 and B32 neurons of the buccal ganglia of Aplysia californica. I. Neurophysiol. 71: 1514-1527.

Hurwitz, I., Neustadter, D., Morton, D., Chiel, H., and Susswein, A.J. 1996. Activity patterns of the B31/32 pattern initiators innervating the $\mathrm{I} 2$ muscle of the buccal mass during normal feeding movements in Aplysia californica. J. Neurophysiol. 75: 1309-1326.

Hurwitz, I., Kupfermann, I., and Weiss, K.R. 2003. Fast synaptic connections from CBIs to pattern-generating neurons in Aplysia: Initiation and modification of motor programs. J. Neurophysiol. 89: 2120-2136.

Hyman, S.E. 2005. Addiction: A disease of learning and memory. Am. J. Psychiatry 162: 1414-1422.

Jay, T.M. 2003. Dopamine: A potential substrate for synaptic plasticity and memory mechanisms. Prog. Neurobiol. 69: 375-390.

Jing, J. and Weiss, K.R. 2001. Neural mechanisms of motor program switching in Aplysia. J. Neurosci. 15: 7349-7362.

Jing, J. and Weiss, K.R. 2005. Generation of variants of a motor act in a modular and hierarchical motor network. Curr. Biol. 15: 1712-1721.

Jing, J., Cropper, E.C., Hurwitz, I., and Weiss, K.R. 2004. The construction of movement with behavior-specific and behavior-independent modules. J. Neurosci. 24: 6315-6325.

Jones, N., Kemenes, G., and Benjamin, P.R. 2001. Selective expression of electrical correlates of differential appetitive classical conditioning in a feeding network. J. Neurophysiol. 85: 89-97.

Kabotyanski, E., Baxter, D., and Byrne, J. 1998. Identification and characterization of catecholaminergic neuron B65, which initiates and modifies patterned activity in the buccal ganglia of Aplysia. J. Neurophysiol. 79: 605-621.

Kabotyanski, E.A., Baxter, D.A., Cushman, S.J., and Byrne, J.H. 2000. Modulation of fictive feeding by dopamine and serotonin in Aplysia. J. Neurophysiol. 83: 374-392.

Kandel, E.R. 1979. Behavioral biology of Aplysia. Freeman, San Francisco.

Katzoff, A., Ben-Gedalya, T., and Susswein, A.J. 2002. Nitric oxide is necessary for multiple memory processes after learning that a food is inedible in Aplysia. J. Neurosci. 22: 9581-9594.

Kelley, A. 2004. Memory and addiction: Shared neural circuitry and molecular mechanisms. Neuron 44: 161-179.

Kelley, A. and Berridge, K. 2002. The neuroscience of natural reward: Relevance to addictive drugs. J. Neurosci. 22: 3306-3311.

Kemenes, G. and Benjamin, P.R. 1989. Appetitive learning in snails shows characteristics of conditioning in vertebrates. Brain Res. 489: 163-166.

\section{Learning \& Memory}


Kemenes, G. and Benjamin, P.R. 1994. Training in a novel environment improves the appetitive learning performance of the snail, Lymnaea stagnalis. Behav. Neural Biol. 61: 139-149.

Kemenes, I., Straub, V., Nikitin, E.S., Staras, K., O'Shea, M., Kemenes, G., and Benjamin, P.R. 2006. Role of delayed nonsynaptic neuronal plasticity in long-term associative memory. Curr. Biol. 16: 1269-1279.

Kim, J.J. and Jung, M.W. 2006. Neural circuits and mechanisms involved in Pavlovian fear conditioning: A critical review. Neurosci. Biobehav. Rev. 30: 188-202.

Kojima, S., Nanakamura, H., Nagayama, S., Fujito, Y., and Ito, E. 1997. Enhancement of an inhibitory input to the feeding central pattern generator in Lymnaea stagnalis during conditioned taste-aversion learning. Neurosci. Lett. 230: 179-182.

Kojima, S., Hosono, T., Fujito, Y., and Ito, E. 2001. Optical detection of neuromodulatory effects of conditioned taste aversion in the pond snail Lymnaea stagnalis. J. Neurobiol. 49: 118-128.

Kupfermann, I. 1974. Feeding in Aplysia: A simple system for the study of motivation. Behav. Biol. 10: 1-26.

Kupfermann, I. and Weiss, K. 2001. Motor program selections in simple model systems. Curr. Opin. Neurobiol. 11: 673-677.

Lechner, H., Baxter, D.A., and Byrne, J.H. 2000a. Classical conditioning of feeding in Aplysia: I. Behavioral analysis. J. Neurosci. 20: $3369-3376$.

Lechner, H., Baxter, D.A., and Byrne, J.H. 2000b. Classical conditioning of feeding in Aplysia: II. Neurophysiological correlates. J. Neurosci. 20: $3377-3386$.

Liu, Z., Richmond, B.J., Murrray, E.A., Saunders, R.C., Steenrod, S., Stubblefield, B.K., Montague, D.M., and Ginns, E.I. 2004. DNA targeting of rhinal cortex D2 receptor protein reversibly blocks learning cues that predict reward. Proc. Natl. Acad. Sci.

101: 12336-12341.

Lorenzetti, F.D. and Byrne, J.H. 2002. Aplysia: Classical conditioning and operant conditioning. In Learning and memory, 2d ed. (ed. J.H. Byrne) pp. 33-37. MacMillan Publishing Company, New York.

Lorenzetti, F.D., Baxter, D.A. and Byrne, J.H. 2006a. Both PKA and PKC are necessary for plasticity in a single cell analogue of operant conditioning. Abstract Viewer/Itinerary Planner, Program No. 669.8. Society for Neuroscience, Washington, D.C.

Lorenzetti, F.D., Mozzachiodi, R., Baxter, D.A., and Byrne, J.H. 2006b. Classical and operant conditioning differentially modify the intrinsic properties of an identified neuron. Nat. Neurosci. 9: 17-19.

Maren, S. 2005. Synaptic mechanisms of associative memory in the amygdala. Neuron 15: 783-786.

Martin-Soelch, C., Missiner, J., Leenders, K.L., and Schultz, W. 2003. Neural activity related to the processing of increasing monetary reward in smokers and nonsmokers. Eur. J. Neurosci. 18: 680-688.

Maximova, O.A. and Balaban, P.M. 1984. Neuronal correlates of aversive learning in command neurons for avoidance behavior of Helix lucorum L. Brain Res. 292: 139-149.

Montague, P.R., McClure, S.M., Baldwin, P.R., Phillips, P.E.M., Budygin, E.A., Stuber, G.D., Kilpatrick, M.R., and Wightman, R.M. 2004. Dynamic gain control of dopamine delivery in freely moving animals. J. Neurosci. 24: 1754-1759.

Morgan, P.T., Perrins, R., Lloyd, P.E., and Weiss, K.R. 2000. Intrinsic and extrinsic modulation of single central pattern generating circuit. $J$. Neurophysiol. 84: 1186-1193.

Morgan, P.T., Jing, J., Vilim, F.S., and Weiss, K.R. 2002. Interneuronal and peptidergic control of motor pattern switching in Aplysia. $J$. Neurophysiol. 87: 49-61.

Morton, D. and Chiel, H. 1993a. In vivo buccal nerve activity that distinguishes ingestion from rejection can be used to predict behavior transitions in Aplysia. J. Comp. Physiol. [A] 172: 17-32.

Morton, D. and Chiel, H. 1993b. The timing of activity in motor neurons that produce radula movements distinguishes ingestion from rejection in Aplysia. J. Comp. Physiol. [A] 173: 519-536.

Mozzachiodi, R., Lechner, H., Baxter, D.A., and Byrne, J. 2003. In vitro analog of classical conditioning of feeding behavior in Aplysia. Learn. Mem. 10: 478-494.

Mozzachiodi, R., Baxter, D.A., and Byrne, J.H. 2006. Enduring changes in the intrinsic excitability of an identified neuron contribute to long-term memory following operant conditioning. Abstract Viewer/Itinerary Planner, Program No. 669.9. Society for Neuroscience, Washington, D.C.

Mpitsos, G.J. and Cohan, C.S. 1986a. Comparison of differential Pavlovian conditioning in whole animals and physiological preparations of Pleurobranchaea: Implications of motor pattern variability. J. Neurobiol. 17: 499-516.

Mpitsos, G.J. and Cohan, C.S. 1986b. Differential Pavlovian conditioning in the mollusc Pleurobranchaea. J. Neurobiol. 17: 487-497.

Nargeot, R., Baxter, D.A., and Byrne, J.H. 1997. Contingent-dependent enhancement of rhythmic motor patterns: An in vitro analog of operant conditioning. J. Neurosci. 17: 8093-8105.

Nargeot, R., Baxter, D.A., and Byrne, J.H. 1999a. In vitro analog of operant conditioning in Aplysia. I. Contingent reinforcement modifies the functional dynamics of an identified neuron. $J$. Neurosci. 15: 2247-2260.

Nargeot, R., Baxter, D., and Byrne, J. 1999b. In vitro analog of operant conditioning in Aplysia. II. Modifications of the functional dynamics of an identified neuron contributes to motor pattern selection. $J$. Neurosci. 19: 2261-2272.

Nargeot, R., Baxter, D.A., Patterson, G.W., and Byrne, J.H. 1999c. Dopaminergic synapses mediate neuronal changes in an analogue of operant conditioning. J. Neurophysiol. 81: 1983-1987.

Nikitin, V.P. 1994. Molecular-cellular mechanisms of learning of the common snail. Neurosci. Behav. Physiol. 24: 321-328.

Nikitin, V.P., Kozyrev, S.A., Gvozdeva, M.M., Shevelkin, A.V., and Sherstnev, V.V. 1994. Protein-synthesis blockers reproduce the effect of nociceptive sensitization on the defense and food reactions in the snail. Zh. Vyssh. Nerv. Deiat. Im. I P Pavlova 44: 1004-1015.

Orekhova, I.V., Jing, J., Brezina, V., DiCaprio, R.A., Weiss, K.R., and Cropper, E.C. 2001. Sonometric measurements of motor-neuron-evoked movements of an internal feeding structure (the radula) in Aplysia. J. Neurophysiol. 86: 1057-1061.

Pavlov, I. 1927. Conditioned reflexes: An investigation of the physiological activity of the cerebral cortex. Oxford University Press, London.

Plummer, M. and Kirk, M. 1990. Premotor neurons B51 and B52 in the buccal ganglia of Aplysia californica. J. Neurophysiol. 63: 539-557.

Reyes, R.D., Mozzachiodi, R., Baxter, D.A., and Byrne, J.H. 2005. Reinforcement in an in vitro analog of appetitive classical conditioning of feeding behavior in Aplysia: Blockade by a dopamine antagonist. Learn. Mem. 12: 216-220.

Robleto, K., Poulos, A.M., and Thompson, R.F. 2004. Brain mechanisms of extinction of the classically conditioned eyeblink response. Learn. Mem. 11: 517-524.

Rosen, S., Weiss, K., and Kupfermann, I. 1979. Response properties and synaptic connections of mechanoafferent neurons in cerebral ganglion of Aplysia. J. Neurophysiol. 42: 954-974.

Rosen, S., Weiss, K., Cohen, J., and Kupfermann, I. 1982. Interganglionic cerebral-buccal mechanoafferents of Aplysia: Receptive fields and synaptic connections to different classes of neurons involved in feeding behavior. J. Neurophysiol. 48: 271-288.

Rosen, S., Teyke, T., Miller, M., Weiss, K., and Kupfermann, I. 1991. Identification and characterization of cerebral-to-buccal interneurons implicated in the control of motor programs associated with feeding in Aplysia. J. Neurosci. 11: 3630-3655.

Sahley, C.L. 1995. What we have learned from the study of learning in the leech. J. Neurobiol. 27: 434-445.

Sahley, C.L., Martin, K.A., and Gelperin, A. 1990. Analysis of associative learning in the terrestrial mollusc Limax maximus. II. Appetitive learning. J. Comp. Physiol. [A] 167: 339-345.

Sanchez, J. and Kirk, M. 2001. Cerebral-buccal pathways in Aplysia californica: Synaptic connections, cooperative interneuronal effects and feedback during buccal motor programs. J. Comp. Physiol. [A] 187: 801-815.

Sanchez, J. and Kirk, M. 2002. Ingestion motor programs of Aplysia are modulated by short-term synaptic enhancement in cerebral-buccal interneuron pathways. Invert. Neurosci. 4: 199-212.

Sanchez, J., Li, Y., and Kirk, M. 2000. Regeneration of cerebral-buccal interneurons and recovery of ingestion buccal motor programs in Aplysia after CNS lesions. J. Neurophysiol. 84: 2961-2974.

Schultz, W. 1997. Dopamine neurons and their role in reward mechanisms. Curr. Opin. Neurobiol. 7: 1983-1987.

Schultz, W. 2001. Reward signaling by dopamine neurons. Neuroscientist 7: 293-302.

Schultz, W. 2002. Getting formal with dopamine reward. Neuron 36: $241-263$.

Schwarz, M. and Susswein, A.J. 1984. A neural pathway for learning that food is inedible in Aplysia. Brain Res. 294: 363-366.

Schwarz, M. and Susswein, A.J. 1986. Identification of the neural pathway for reinforcement of feeding when Aplysia learn that food is inedible. J. Neurosci. 6: 1528-1536.

Shizgal, P. and Murray, B. 1989. Neuronal basis of intracranial self-stimulation. In The neuropharmacological basis of reward (eds. J.M. Liebman and S.J. Cooper), pp. 106-163. Oxford University Press, New York.

Skinner, B. 1938. The behavior of organisms: An experimental analysis. Appleton-Century-Crofts, New York.

Stefani, M.R. and Moghaddam, B. 2006. Rule learning and reward contingency are associated with dissociable patterns of dopamine activation in the rate prefrontal cortex, nucleus accumbens, and dorsal striatum. J. Neurosci. 23: $8810-8818$.

Stein, L. and Belluzzi, J.D. 1989. Cellular investigation of behavior 
reinforcement. Neurosci. Biobehav. Rev. 13: 69-80.

Stein, L., Xue, B.G., and Belluzzi, J.D. 1993. A cellular analogue of operant conditioning. J. Exp. Anal. Behav. 60: 41-53.

Straub, V., Kemenes, I., O'Shea, M., and Benjamin, P.R. 2006.

Associative memory stored by functional novel pathway rather than modifications of preexisting neuronal pathways. J. Neurosci. 26: 4139-4146.

Susswein, A. and Byrne, J. 1988. Identification and characterization of neurons initiating patterned activity in the buccal ganglia of Aplysia. J. Neurosci. 8: 2049-2061.

Susswein, A. and Schwartz, M. 1983. A learned change of response to inedible food in Aplysia. Behav. Neural Biol. 39: 1-6.

Susswein, A., Schwartz, M., and Feldman, E. 1986. Learned changes of feeding behavior in Aplysia in response to edible and inedible foods. J. Neurosci. 6: 1513-1527.

Teyke, T., Rosen, S.C., Weiss, K.R., and Kupfermann, I. 1993.
Dopaminergic neuron B20 generates rhythmic neuronal activity in the feeding motor circuitry of Aplysia. Brain Res. 630: 226-237.

Thorndike, E. 1911. Animal intelligence: Experimental studies. MacMillian, New York.

Tobler, P.N., Fiorillo, C.D., and Schultz, W. 2005. Adaptive coding of reward value by dopamine neurons. Science 307: 1642-1645.

Wise, R.A. 2004. Dopamine, learning and motivation. Nat. Rev. Neurosci. 5: $1-12$.

Wise, R.A. 2005. Forebrain substrates of reward and motivation. J. Comp. Neurol. 493: 115-121.

Xin, Y., Weiss, K., and Kupfermann, I. 1995. Distribution in the central nervous system of Aplysia of afferent fibers arising from cell bodies located in the periphery. J. Comp. Neurol. 359: 627-643.

Ye, H., Morton, D., and Chiel, H. 2006. Neuromechanics of coordination during swallowing in Aplysia californica. J. Neurosci. 26: $1470-1485$. 


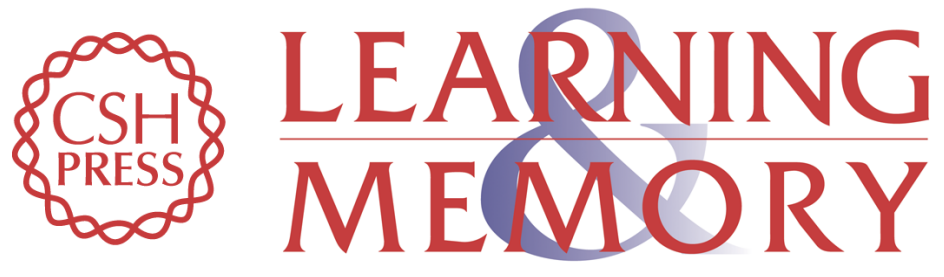

\section{Feeding behavior of Aplysia: A model system for comparing cellular mechanisms of classical and operant conditioning}

Douglas A. Baxter and John H. Byrne

Learn. Mem. 2006, 13:

Access the most recent version at doi:10.1101//m.339206

References This article cites 108 articles, 30 of which can be accessed free at: http://learnmem.cshlp.org/content/13/6/669.full.html\#ref-list-1

License

Email Alerting Receive free email alerts when new articles cite this article - sign up in the box at the Service top right corner of the article or click here. 